\title{
Atisbos a la subjetividad de los victimarios en el cine y el ciberespacio en México
}

\author{
Traces of subjectivity in the victimizers \\ in cinema and cyberspace in Mexico
}

\author{
Héctor Dominguez Ruvalcaba* \\ The University of Texas at Austin, Austin, Estados Unidos. \\ ORCID: https://orcid.org/o000-0002-I4I3-8196 \\ ISSN: ISSN-OI85-4259; e-ISSN: 2007-9176
}

DOI: http://dx.doi.org/I0.28928/revistaiztapalapa/7920I5/aotI/dominguezruvalcabah

\section{Resumen}

Este artículo se propone discutir la subjetividad del perpetrador de violencia de género con base en algunas representaciones cibernética y fílmica. Los principales problemas que aborda son: la articulación de una política del odio misógino y homofóbico en los comentarios de los lectores a la prensa en línea; el papel de las autoridades en la perpetuación de la violencia, en la película Señorita extraviada de Lourdes Portillo; la economía del consumo violento de cuerpos desechables en la serie de animación El Verguillas; y la caracterización del goce violento en el documental Narcocultura.

Palabras clave: odio, crueldad, feminicidios, homofobia, cuerpos desechables

\footnotetext{
Abstract

Abstract: This article's goal is to discuss the subjectivity of perpetrators of sex-gender violence in Mexico as represented in film and the cyberspace. The main problems addressed are: the articulation of a politics of homophobic and misogynistic hate in the reader's comments sections of the on-line news; the role of authorities in the perpetuation of violence, in Señorita Extraviada by Lourdes Portillo; the economics of violent consumption of disposable bodies in the animation series El Verguillas; and the characterization of the violent pleasure in the film Narcocultura by Shaul Schwarz.

Keywords: Hatred, cruelty, feminicides, homophobia, disposable bodies
}

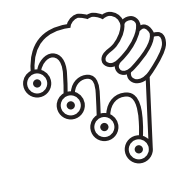

\section{IZTAPALAPA}

Agua sobre lajas

Doctor en Literatura Latinoamericana. Profesor-investigador especializado en sexualidad, género $y$ violencia en la literatura y la cultura latinoamericanas, enfocado en el México contemporáneo y la región fronteriza con Estados Unidos. ruvalcaba@austin.utexas.edu 
$B$ eneficiarios de una impunidad ilimitada que generosamente les otorga el sistema mexicano de corrupción, los sujetos feminicidas se nos presentan como personajes míticos por ser invisibles e intangibles, aunque paradójicamente los rastros de su violencia se cuentan entre las mayores expresiones de los excesos humanos de nuestro tiempo. Sabemos que los feminicidas existen porque los cadáveres son testimonio de sus actos. Sabemos que tienen subjetividad porque en esos cadáveres han inscrito su odio. $\mathrm{O}$ por lo menos suponemos que sus actos de crueldad sobre la víctima expresan la humillación y destrucción de un cuerpo porque se le odia. Según el Diccionario de la lengua española, de la Real Academia, odio es 'antipatía y aversión hacia algo o hacia alguien cuyo mal se desea'. Este concepto se acerca al de fobia, pues comparte con ella el elemento de aversión, lo que psicoanalíticamente se entiende como un miedo irracional a algo o alguien a quien se desea destruir compulsivamente. Para Charles Odier, este miedo se manifiesta frente a un "objeto fobógeno [que] está dotado de todos los atributos de una fuerza maléfica" (Odier, I961:66, en cursivas en el original). De acuerdo con este punto de vista, la saña que suele acompañar a los crímenes por odio sexogenérico sería entonces expresión de miedo ante un sujeto que es percibido como portador del mal. No se trata de una mera patología en la que el miedo irracional se manifiesta como síntoma de una personalidad excepcional. Despatologizar el odio sexogenérico nos exige entonces volver los ojos sobre los factores de la política de género, la que se libra en el plano de las relaciones de poder entre las diversas identidades en su interacción cotidiana.

En este plano de lo político, el carácter compulsivo de la victimización en los casos de feminicidios y odio homofóbico no es atribuible a una mera condición neurótica o psicótica, en tanto que no podemos hablar de un desequilibrio excepcional en este tipo de conductas. Por el contrario, los crímenes sexogenéricos son expresiones de una normatividad, lo que añade al odio una sanción social, esto es, el odio se afirma en un consenso que lo normaliza. Puede, sin embargo, argumentarse que la violencia sexogenérica sucede en violación a la norma social y que, por tanto, se ha sancionado socialmente como crimen. No obstante, la violencia feminicida y homofóbica no podría entenderse sin la referencia a la normatividad de género que le da sentido. 
La subjetividad del emisor de violencia de género se articula entonces a partir de la normatividad genérica. Puede, por ello, plantearse que las manifestaciones de odio misógino y homofóbico son expresiones de una norma patriarcal que atentan contra los derechos humanos de las víctimas. Puede entonces sostenerse que los pactos patriarcales, en los cuales, según Celia Amorós, se articulan las estrategias de dominación del patriarcado, se ven afectados por el discurso de los derechos humanos (Amorós 1990:4I). Esto termina por evidenciarse cuando analizamos los debates que han ocupado la esfera pública en torno a la violencia feminicida en México. Mientras que organizaciones e instituciones nacionales e internacionales de derechos humanos han insistido en que se realicen investigaciones transparentes y se combata la corrupción y la impunidad, los actos oficiales se reducen a simular que se investiga y a perseguir a los activistas menos permeables a la cooptación: una categoría de exiliados mexicanos en Estados Unidos está directamente relacionada con el activismo derechohumanista en torno a la violencia de género: el caso de Juan Freire Escobedo, por ejemplo, muestra cómo, lejos de seguir las recomendaciones en torno a las violaciones a los derechos humanos, los agentes del Estado se han interesado en amenazar y eliminar a quienes abogan por las demandas de seguridad para las mujeres (Aguilar, 2012). Freire tuvo que huir del país por amenazas de muerte recibidas por su activismo tras haber sido asesinada su madre, Marisela Escobedo, frente al palacio de gobierno de Chihuahua, mientras hacía un plantón en protesta por la impunidad otorgada al homicida de su hija Rubí Freire. El asesino de Rubí es miembro de una organización criminal y goza de impunidad: se trata de un esquema de colusión gobierno-cárteles como agente violador de los derechos humanos.

El odio feminicida y homofóbico no es solamente una expresión de revancha de los hombres que ven sus privilegios afectados por la visibilidad y el avance de los derechos de las mujeres y las minorías sexuales, es también una agenda gubernamental, por lo menos de algunos agentes del estado que con su negligencia, omisión, y sus actos subrepticios, de acoso a los defensores de los derechos de los sujetos vulnerados por el odio sexogenérico, muestran una voluntad de mantener y fortalecer el sistema de impunidad que se ha vuelto endémico. Marcela Lagarde entiende que el feminicidio no se define solamente como el asesinato de mujeres por el hecho de ser mujeres, que en la tradición feminista anglosajona se ha denominado femicide (Radford y Russell, 1992), sino que, además, implica el contexto de impunidad y de desprotección de los ciudadanos por parte del Estado (Lagarde, 20II:I9). La sistematización de la violencia sexogenérica corre a cargo, entonces, de una asociación política entre las fuerzas del Estado y las fuerzas criminales favorecidas por las garantías de impunidad que les brinda el aparato gubernamental. 


\section{Racionalizando la violencia patriarcal: la homofobia}

Dada la amplia libertad de actuar, los perpetradores de esta violencia han logrado desarrollar un discurso que fantasea con el exterminio de las diversidades sexuales, que se ha expresado ampliamente en los discursos sociales y que cuenta con las tecnologías de representación más atendidas en el presente. Los elementos que constituyen esta subjetividad depredadora los identifica Carlos Monsiváis (2006) al comentar la ola de violencia feminicida y homofóbica en México $a$ ) [los asesinos] no conocían previamente a sus víctimas; b) el asesinato fue un acto de placer homicida, porque el propósito último, evidente, era destruir a la especie representada por la persona indefensa; $c$ ) el odio explica la cuantía y la profundidad de la saña; d) los delincuentes carecen de remordimiento.

Me interesa retomar esta clasificación de Monsiváis como un punto de partida para abordar el análisis de las representaciones de los asesinos en el cine y el ciberespacio. Monsiváis plantea que el asesinato no está determinado por los actos, actitudes, opiniones o creencias de la víctima. La subjetividad de esta no juega ningún papel en la relación violenta. El victimario tiene entonces motivaciones que pueden deducirse de la misma elección del cuerpo victimizado: edad, raza, sexualidad, rasgos de pertenencia a determinado grupo social, formas, gestos, movimientos, y su entorno, pues el espacio que lo rodea forma también parte de la semiótica del cuerpo. Entendemos entonces que el victimario atiende a una codificación del cuerpo sometible. No mata a cualquier cuerpo, sino a aquellos que se han clasificado como eliminables. Carlos Monsiváis cita a algunos asesinos por odio homofóbico para sugerir que ellos fundan su motivación en el discurso hegemónico de género: Marroquín Reyes, el sádico, dice que hacía un bien a la sociedad al secuestrar y asesinar homosexuales (Reséndiz, 2013). En los comentarios de los lectores a la nota de Francisco Reséndiz alusiva a la detención de Marroquín, las celebraciones de torturas y asesinatos cometidos por este exmilitar muestran la amplia aceptación del odio homofóbico en México, y cómo a sus ojos las víctimas merecían el castigo; los asesinatos por homofobia, tanto como los motivados por misoginia, parecen estar respaldados por una ideología reivindicativa de la dominación masculina; desde esa perspectiva, las mujeres y los homosexuales han dejado de cumplir con las expectativas de género.

Tomados al azar, de tantos que se pueden localizar en línea, podemos citar los siguientes comentarios de lectores, por considerarlos parte de un discurso del odio que ha ocupado el espacio cibernético:

En la versión digital del periódico El economista del I7 de mayo de 20I4, en un comentario al artículo "México ocupa segundo lugar en crímenes de odio: IKos" el 
lector que firma como Anónimo Sebastián escribió: “Terrible que se asesine a los homosexuales o cualquier persona, pero también terrible que traten de imponer en nuestras sociedades perversiones como la homosexualidad y tratar de hacerlas parecer como normales"' "México ocupa segundo lugar en crímenes de odio: IKOs"). A la vez que reprueba el asesinato de los homosexuales, este lector también reprueba lo que él percibe como una perversión que se impone a nuestras sociedades y se pronuncia contra la inclusión ciudadana de estas personas. En este comentario se reitera la consigna católica de "amamos al pecador pero condenamos su pecado" que condiciona la inclusión de los homosexuales en su marco de ciudadanía siempre y cuando nieguen su propia orientación sexual.

El I9 de marzo de 20I4, Daniel Herrera comenta la nota "Instruye GDF instrumentar acciones contra la homofobia”, aparecida en la versión digital de El Universal: "¿Y no te da pena y hasta asco cuando pasas por la zona rosa? La verdad ahí está muy cabrón el asunto, pero eso sí, de eso no les gusta quejarse" (sic). Herrera alude a la condición abyecta con que la visión patriarcal dominante percibe el cuerpo homosexual. Se trata de cuerpos que deberían dar asco para esta visión intolerante. Esto es, el comentario promueve la aversión como gesto moral y juzga el discurso oficial de la ciudad de México como defensor de lo que debería condenar. En ambos comentarios priva el mismo celo piadoso con que Marroquín Reyes, el sádico, justifica sus crímenes homofóbicos, con lo que podemos afirmar que el asesino no hace más que cumplir el deseo social que el patriarcado ha forjado a través de sus aparatos ideológicos como la iglesia y los medios.

El comentario de Pedro Reyes a la nota de Héctor Alonso Morales, "Piden gritar 'tuzo' y no pu... a arquero rival" aparecida el i8 de marzo de 2014 en la versión en línea de El Universal, hace un llamado al exterminio: "sí, que a puñales y maricas los echen al cráter del Popocatépetl iii” (sic). El tono de este comentario pretende ser divertido y los límites entre la broma y el insulto parecen borrosos, pero ello no dispensa el lenguaje del odio. Entre el extrañamiento del que interpreta su odio como acto piadoso y la consigna de exterminio contra los sujetos diversos, los comentarios a las noticias que versan sobre homofobia en la prensa mexicana son un bastión de lucha machista contra los derechos humanos de la población LGBT. El ciberespacio se convierte en una arena ideológica donde podemos asomarnos a los mandatos sociales y religiosos que respaldan el crimen sexogenérico. La subjetividad del criminal tiene en estas expresiones de abyección piadosa su contenido ideológico. El anonimato que ofrece el ciberespacio permite asomarnos al sentido de su odio, un celo patriarcal revestido de consignas religiosas. 


\section{Los invisibles, los inefables feminicidas}

$\mathrm{Al}$ contrario de los comentaristas homofóbicos, no contamos con el discurso de los asesinos seriales que gozan de impunidad por los feminicidios de Ciudad Juárez, no podríamos asomarnos a su subjetividad porque los esfuerzos del aparato oficial se han empeñado en ocultarla. Contamos, sin embargo, con las declaraciones de funcionarios que al igual que los esposos ofendidos de la violencia doméstica explican los feminicidios culpando a las mujeres de su victimización. En plan defensivo, las autoridades acusan a las mujeres de vestir provocativamente, caminar en la calle por la noche o dedicarse al servicio sexual: todas ellas conductas no sancionadas en las normas del Estado sino en el discurso de la moral patriarcal. En el documental de la cineasta mexicana-estadounidense Lourdes Portillo, Señorita extraviada (200I), se presenta la declaración del gobernador Francisco Barrio: "Se ha encontrado un patrón muy parecido. Las muchachas se mueven en ciertos lugares, encuentran a cierto tipo de gente y entran en una cierta confianza con malvivientes, con gente de bandas que luego se convierten en sus agresores". El gobernador imagina una escena donde la imprudencia de la víctima la hace caer en la trampa de los victimarios. Ellos cumplen con el papel masculino de acechar a sus presas sexuales y, a los ojos del gobernador, al parecer no son condenables, como sí lo son el vestido y el uso del espacio urbano de las mujeres. Así, la sexualidad violenta se articula como una escena de cacería aceptada por la autoridad, para quien el inexorable instinto masculino no es materia de acción penal. El documental de Portillo, junto con el libro El silencio que la voz de todas quiebra (Rhory Benítez et al., 1999), fueron dos de las respuestas más tempranas a esta visión misógina de las autoridades y su recurrente difamación de las víctimas. La impunidad y el desaseo en las investigaciones sobre los feminicidios se despliegan a lo largo de diversos testimonios de víctimas y activistas.

Tenemos, entonces, que en el fondo del discurso misógino se encuentra una norma patriarcal que determina que las instituciones protejan a los victimarios. Esto es, la persistencia de la impunidad en los casos de los feminicidios muestra que se trata de un sistema organizado en torno a garantizar el goce de matar de un grupo de individuos que cuentan con recursos para detener el efecto de la ley. Ese sistema protege a sujetos que victimizan a otros sujetos y los vacían de su subjetividad para sellar su dominio. Los campos de representación de la misoginia nos permiten plantear que el sujeto violento depende tanto de la objetivación de las víctimas como de la normativización de la violencia, esto es, la sistematización de la impunidad como norma. El depredador sexogenérico no es un sujeto extraordinario sino una subjetividad reproducida socialmente, donde un factor constante es el despliegue 
de fuerza, una práctica de dominación y, por lo tanto, un proyecto político. De acuerdo con el sociólogo Hugo Zemelman (2000:159) “[e]l proyecto político es el fin, o dirección, propuesto por una voluntad colectiva en circunstancias que lo especifican históricamente". Aunque las referencias empíricas de Zemelman se ubican en el terreno de las reivindicaciones comunitarias, me interesa destacar las nociones de voluntad colectiva y la finalidad para comprender los actos de violencia sexogenérica como parte de un proyecto político misógino. La impunidad activa de las autoridades deja claro que existe una colusión de sujetos que juzga necesaria una acción destructiva para apuntalar la supremacía masculina. Marroquín Reyes ubica como el mal la existencia de homosexuales en la vía pública, pues en su opinión estos afectan el orden heterosexual cristiano, y el gobernador de Chihuahua no se alarma ante la proliferación de feminicidios sino ante la conducta insumisa de las mujeres que procuran su propia independencia: en ambos casos puede leerse un mandato patriarcal como principio de justificación de la violencia homofóbica y misógina.

¿Pero cuán hegemónica es esta posición supremacista? ¿Qué formas de respuesta pueden advertirse en el espacio virtual? El ciberespacio, en su carácter interactivo, se ha constituido como un instrumento de evaluación colectiva de las expresiones sociales. En mayo de 2014 circuló en redes sociales una serie de fotografías de una campaña misógina emprendida por la estación de radio La Mejor 95.5, en Guadalajara. Esta emisora, especializada en música grupera, hizo pintar frases en las bardas de la ciudad donde claramente se denigraba a las mujeres: "Traes tupperware porque te daré hasta pa' llevar"; "Si me vas a dejar, que sea embarazada"; "¿Qué somos? Mujeres, y ¿qué queremos? No sabemos, somos mujeres,; "Aunque la fresa se vista de seda, peda se encuera". La reacción en redes sociales fue contundente y la presión ciudadana por que se borrara esta publicidad fue amplia. Este campo simbólico de lucha nos confirma que, en efecto, hay una construcción política misógina que se expresa en lenguaje denigratorio de las mujeres, a las cuales ubica en el plano de cuerpo para el sexo y máquina de reproducción carente de raciocinio. Se trata de una construcción heterónoma del sujeto femenino, el cuerpo que el sujeto misógino quiere ver bajo su dominio. El sujeto violento crea entonces las condiciones y el espacio para su actuación destructiva.

Más que no conocer a la víctima, como plantea Monsiváis, se debe decir que los asesinos producen la identidad de la víctima al ejercer una lectura corporal donde los signos de la vulnerabilidad están presentes. Esto es, en el marco de representación de la mujer como suplemento de la virilidad, se la desea vulnerable, extinguible, o desechable (Melissa Wright, 2006). Esta identidad creada para el deseo destructivo es el principal criterio para la selección de la presa. ¿Cómo les llaman 
los victimarios a sus víctimas en los casos de violencia sexogenética? El proferir de la injuria pornográfica arrojada como gesto de lujuria y de dominio cumple la función de una sentencia que es euforia sexual y tanática. Matar por odio de género es una escenificación de cuerpos que despliegan el espectáculo de la humillación. Se trata de una voluntad de destruir a la especie femenina y a todo lo que no cumple con los rasgos de la masculinidad dominante. En este sentido, el asesinato de odio feminicida es también un genocidio.

Tanto la política del odio homofóbico como del misógino cuentan con el respaldo de la religión y las instituciones generadoras de impunidad. Se trata de los mecanismos ideológicos del patriarcado ante los cuales no han faltado expresiones críticas como los documentales y los debates de las redes sociales. Tal es el campo representacional que nos permite reconocer la violencia sexogenérica como una violencia institucionalizada.

\section{La institucionalización del crimen misógino}

El exceso de la saña aplicada no solo puede leerse en los últimos estertores del cuerpo moribundo sino también en esa falta de remordimiento que distancia al asesino de la significación de su acto. Cuando el asesinar carece de culpa, además de la ley que prohíbe matar, se derogan las líneas que definen a lo humano. Lejos de un simple acto excepcional estamos ante una voluntad sistemática de destruir a la especie. Cuando hablo de la deshumanización del victimario quiero entender un proceso de pérdida del sentido en el plano de las significaciones éticas y políticas. La ausencia de valor de la vida humana, avalada por las instituciones, aunque sea por omisión, trasciende a lo colectivo para producir una ausencia de las bases que sustentan al Estado.

Uno de los testimonios más reveladores del documental Señorita extraviada de Portillo (200I) es el de María, una mujer que había sido detenida en Ciudad Juárez por una riña en su barrio, debida a disputas por la propiedad. Ella nos cuenta cómo estando encerrada en la Cárcel de Piedra se resistía a la violación por parte de los policías. Por ello, con la intención de amedrentarla, ellos le mostraron una serie de fotografías donde se veía a varios hombres violando y asesinando mujeres a manera de divertimento:

Las de pelo largo les agarraban del pelo así y luego se lo enredaban en la mano y se las llevaban arrastrando, todas se las llevaban así arrastrando por los matorrales. Y luego se 
ponen así en rueda y luego la ponen así y la acuestan y luego la violan y luego se quita uno y sigue el otro, las voltean, las empiezan a golpear, las voltean y las violan rectalmente. Y así, así entre todos, ¿verdad? Y todos a risa y risa, o sea, se miran en la foto que están a risa y risa. Como que miran pa' bajo y voltean y se sueltan así a carcajadas, riendo, se miran en las fotos que están así riéndose por lo que está haciendo el otro y luego los otros les toman fotos, les están tomando fotos y luego se mira cuando los pezones se los arrancan así a mordidas. Yo me imagino que están cerca pues se miraba muy clarito, así golpeadas, y se les miraba su cara así de dolor, así de sufrimiento y se las miraba así que lloraban y gritaban, y su cara se miraba así, se reflejaba el dolor que ella estaba sintiendo, ¿̇verdad?, por lo que le hacían y se miraban muy tristes... Y los otros muchachos les hacían lo que les hacían y luego les rociaban gasolina y les prendían el cerillo y ahí se quemaban pero ya ellas ya estaban muertas. Y ellos así burlándose en las fotos porque miraban cómo se quemaba la muchacha. Muy feo, pobrecitas (Portillo, 200I, 00:56-00:58).

Los actos del victimario se dirigen a causar humillación. El lenguaje del odio se articula a través de la reducción de la dignidad de la víctima. María está atrapada y sometida por los hombres cuyo papel social, paradójicamente, es hacer cumplir la ley. Ella es acusada de participar en una riña y dicha falta autoriza a los policías a vejarla. Sabemos en otra parte del documental que la violación fue consumada. Ella y su esposo denunciaron a los policías, quienes fueron detenidos y finalmente absueltos. Desde entonces sufrió acosos y amenazas. María cayó en manos de un grupo organizado de agresores sexuales, desde el momento en que entró en la cárcel y una guardia la revisó agresivamente. Como María se resistía a los ataques sexuales de la uniformada, esta la golpeó. Luego los policías le muestran las fotos de violación y asesinato de las mujeres en Lomas de Poleo. María es sometida a una escenificación conminatoria. Los hombres la amenazan con llevarla a Lomas de Poleo y la obligan a ver las imágenes de lo que le pasaría de seguirse resistiendo. En los cuerpos de las mujeres se ve a sí misma. En su lectura de las fotografías, María nos ofrece una versión no solamente del proceso de la humillación y el exterminio, sino también nos deja asomarnos a los rostros de los sujetos que cometieron el acto. Se aprecia en ellos una falta de remordimiento. La hilaridad de los hombres ante la agonía de la víctima nos abre interrogantes sobre la naturaleza del goce feminicida. La risa de los violadores y asesinos parece sustentarse en la supremacía, esto es: la victimización produce el sentimiento de poder dominar y disponer de otro cuerpo. Los policías usan las representaciones del acto feminicida como una amenaza, con ello son también un instrumento para producir otras victimizaciones. Esto es, ese goce del privilegio de matar se replica infinitamente a la manera de una adicción, la adicción de dominar. 
Este sistema instala su práctica de exterminio contra las mujeres y otros sujetos vulnerados como la población no heterosexual. La representación del goce supremacista cumple entonces la función de una pedagogía de terror. Se exhibe el acto de ejercer violencia sexual hasta la muerte como una forma de control de los cuerpos. La ciudadanía no cuenta con la protección legítimamente establecida, puesto que los uniformados han convertido su trabajo en una máquina genocida. Gozar de la protección institucional para matar termina siendo una marca de prestigio.

Pero además de mirarse a sí misma como víctima en las fotografías de los gendarmes, el testimonio de María le adjudica a la colectividad el papel de víctima potencial. Las mujeres de Lomas de Poleo son trofeos de una cacería abierta que cuenta con la garantía de la impunidad y que elige a su antojo los cuerpos sacrificables. Pero el hecho de que se goce de una impunidad para hacer lo que sea no es suficiente explicación de este exterminio. ¿Qué necesidad, qué fantasía o qué falta induce a que esta impunidad se use asesinando brutalmente a las mujeres? De acuerdo con Rebecca E. Biron (200I:I2), el odio misógino es la voluntad de destruir lo femenino, y define un tipo de masculinidad que requiere la agresión a la mujer para afirmarse. La muerte entonces genera un valor simbólico, una ganancia intangible que ostentan los hombres dominantes. En su análisis de ficciones feminicidas, Biron encuentra "the murder of a female character by a male character as a crime not of passion, but rather of crisis in the construction of viable gender relations" (200I :7). $\mathrm{Al}$ exterminar lo femenino, el feminicida está clausurando la posibilidad de las relaciones de género, orden diferenciador que caracteriza al patriarcado. Es decir que el feminicida no solamente está exterminando sistemáticamente a un sector de mujeres sino también amenaza el orden de los géneros. En su comentario de la noción de mal de Schopenhauer, Terri Eagleton sugiere una forma de entender este impulso destructivo del mal como "motivated by a need to obtain relief from the inner torment of what he [Schopenhauer] called the Will; and this relief was to be gained by inflicting that torment on others" (2010:107). La crueldad tiene la intención de aplicar a otros el tormento que vive el perpetrador. Eso quizá explique la hilaridad de los feminicidas que describe María. Sin embargo, más que como un tormento interno, que nos lleva de regreso a las metáforas románticas y barrocas, me interesa caracterizar este impulso criminal en el marco de significación del mercado. Si se ha articulado como una necesidad, la violencia sexual adquiere entonces el valor de mercancía, como los diversos productos adictivos que rinden pingües ganancias al crimen organizado.

Más que una voluntad del mal surgida por un impulso atormentador, como Eagleton nos sugiere en su lectura de Schopenhauer, encontramos un sometimiento 
de los feminicidas a las normas homosociales que promueven la criminalidad como forma de cohesión o como requisito de inclusión en una sociedad que detenta el prestigio de la supremacía masculina, lo que Rita Segato analiza como fratrias (2003). El mal no es entonces un impulso que lleva a actos que el sujeto que los practica considere condenables. Es opinión compartida por Carlos Monsiváis, Pía Lara, Terri Eagleton, Hermann Herlinghaus, entre otros, que estos actos se cometen sin remordimiento. Quiero plantear que no solamente no hay culpa sino que la violencia feminicida y homofóbica se asumen como un deber colectivo, a la manera en que Judith Butler (1997:18) analiza el discurso del odio como un acuerdo social de exclusión y exterminio de otros.

Este deber social, esta orden colectiva de violar, torturar y asesinar constituye la secuencia central y más inquietante de la película Traspatio dirigida por Carlos Carrera sobre un guion de Sabina Berman (2009). Cutberto se siente agraviado porque Juana prefiere vivir libremente su sexualidad a aceptar un noviazgo con él. Los jóvenes juarenses que lo acompañan en la juerga lo inducen a secuestrar a Juana para darle una lección. Cutberto solo quiere obligarla a tener sexo con él como lo tiene con otros hombres, pero sus compañeros imponen las reglas: ella sería violada en forma multitudinaria y finalmente Cutberto habría de asfixiarla con una bolsa de plástico en la cabeza mientras la violaba. En este caso, Cutberto siente culpa e impotencia, pues no es capaz de oponerse a la coerción de sus compañeros. La subjetividad feminicida se construye desde un sistema de reglas en que un grupo estatuye un placer obligatorio, un mal que es normativo y por lo tanto ejerce un tipo de política, impone una serie de prácticas y un modo de economía.

Tanto el testimonio de María en Señorita extraviada como el episodio de la violación de Juana en Traspatio presentan a los depredadores sexuales como grupos que ejercen la violencia en obediencia a normas tomadas colectivamente por estos victimarios. Pareciera entonces que los pactos patriarcales teorizados por Celia Amorós se manifiestan en estos casos como una normatividad del goce sexual asociado a la muerte, donde exterminar mujeres les ofrece beneficios simbólicos y económicos, lo que se puede interpretar como una economía de la muerte, como veremos en el siguiente apartado.

\section{La economía del exterminio y el mercado de los cuerpos desechables}

Tanto las disputas por la representación de la violencia en el ciberespacio como las obras cinematográficas que circulan en el universo representacional del contexto 
neoliberal deben comprenderse como aspectos que se subsumen a un sistema económico de explotación de cuerpos subalternos. En este sistema de exterminio, la gran reserva poblacional que habita los márgenes de nuestra sociedad provee de víctimas y victimarios para el sostenimiento del sistema violento. Podemos concebir a las víctimas de violencia sexogenérica como cuerpos desechables o consumibles en un circuito económico y un patriarcado extremo que requieren de este exterminio. Por otra parte, la pobreza ha entrenado en la belicosidad a un ejército de jóvenes que a falta de otras opciones van siendo incorporados a las pandillas, mafias, y otras empresas que requieren de su fuerza para convertirla en riqueza.

Es en este contexto de la economía de la violencia que surge El Verguillas (Armando Chacón, Luis Saucedo, Salvador Chacón, 2009), serie de animación producida por FAScomedy, un grupo de jóvenes de Ciudad Juárez que desde 2009 ha sido publicada en youtube.com. Los episodios que hasta la fecha han aparecido en línea tratan del ascenso y la decadencia de Francisco Tobareñas, alias El Verguillas. El empresario de boxeo Álvaro, un hombre criollo racista y clasista, cuyo lenguaje está plagado de expresiones discriminatorias, envía al Tío, un mexicano-americano que habla en spanglish, a los barrios bajos a reclutar jóvenes belicosos como Francisco para explotarlos en el negocio del boxeo. Se trata de hecerles creer que ganan en peleas que realmente han sido arregladas con el fin de atraer público. En esta serie encontramos que las clases desprotegidas no cuentan con recursos para sortear la condición de marginación, a menos que vendan su ira (el Verguillas) o su servicio sexual (la Keke, prima del Verguillas). El Verguillas nos deja ver el fatalismo de una barrera impenetrable entre la élite y la periferia, aunque esta última sea indispensable para los negocios de la primera. Así explica Álvaro su decisión de contactar a jóvenes pobres para utilizarlos en su negocio:

Y yo lo mandé [al Tío] a uno de esos barrios, de esos pinches barrios culeros de aquí de Ciudad Juárez. Tú sabes a cuáles piches barrios me refiero. Tú sabes, puro pinche lomero, pura pinche tierra, que parece que los olvidó Dios... ino, no, no, uno de esos pinches barrios! Pues lo chingón de esos barrios es que es lo más cercano a los pinches salvajes que tenemos en la sociedad, cabrón. Entonces yo en la pendeja, se me ocurrió decir... dije: vamos con los pinches salvajes, no va a faltar el pinche salvaje que parta madre, ese pinche nos lo traemos. La pinche gente pendeja lo agarra y hacemos feria. (El Verguillas, Parte I, o:07:45)

Los barrios de Ciudad Juárez son representados como zona de salvajes. Los jóvenes que ahí viven se presentan como poseedores de un elemento lucrativo: son 
belicosos. El personaje Álvaro continuamente expresa asco, desprecio y burla de los pobladores de estos barrios. Los considera estúpidos y de una condición inferior. Sin embargo, le parecen materia explotable, pues pertenecen a la reserva de los excluidos cuya existencia tiene sentido en tanto se puede traducir en ganancia económica. FAScomedy nos ofrece entonces el panorama de una ciudad dividida, de barreras sociales infranqueables $y$, sobre todo, de una multiplicación de hostilidades entre las diferentes identidades que conviven en la frontera. Su etnografía nos recuerda a la que Pablo Vila (2000) realiza sobre las relaciones identitarias repelentes que los grupos sociales de un lado y otro de la frontera establecen. En este paisaje social signado por el odio es que se puede destacar un componente de clase que explica, para los realizadores de El Verguillas, la dimensión económica de la formación de los perpetradores: al mandato del goce homicida articulado en los pactos entre victimarios, como lo vimos en el apartado anterior, se añade su significación económica, donde el verdugo se construye como un productor de riqueza a través de su acción violenta.

Las hostilizaciones identitarias fronterizas no obstan para que el campo de representaciones de la violencia fluya por ambos lados de la frontera. El documental Narcocultura (Shaul Schwarz, 2013) nos permite asomarnos a la atmósfera de peligro que viven los habitantes de Ciudad Juárez, en alternancia con el ambiente donde viven los compositores de narcocorrido de California. Entre estos últimos se enfoca en Édgar Quintero, compositor del grupo Buknas de Culiacán, quien vende sus composiciones sobre hechos sangrientos y loas a los criminales. Lo vemos cantar a capela una composición por la que le han pagado un fajo prominente de dólares: se trata de una descripción de la buena calidad de la droga, la satisfacción de los clientes y un estilo de vida ostentoso, haciendo énfasis en marcas de autos y armas, las bebidas y las mujeres: todos componentes de un retrato del mafioso que vamos a ver proliferar en sitios como El blog del narco. Estamos entonces ante el narcocorrido como publicidad de los criminales, o al menos como celebración de una cultura del exceso, la ostentación y el terror. En Narcocultura vemos a Édgar pasear con su bebé en el parque cantando la más conocida de sus piezas: "Con cuerno de chivo y bazuka en la nuca,/ volando cabezas al que se atraviesa/ somos sanguinarios, locos bien ondeados/ nos gusta matar" (o:II). En una calle pacífica de Los Ángeles en compañía de un bebé, la descripción de la decapitación y la declaración del goce de matar banalizan el hecho de crueldad que narra. Básicamente se trata de una canción donde el cantante toma la voz del sicario y promueve sus habilidades para matar, sobre todo su frialdad, eficiencia y lealtad al jefe. Se trata, en todo caso, de la configuración de un personaje tipo, el modelo del sicario deseable. Las emociones aparecen 
disociadas de los actos. Buknas ejecuta sus canciones con euforia mientras gesticula imitando a los homicidas mercenarios, donde el erotismo y el placer de matar convergen. Las secuencias del documental se alternan entre las actividades de los cantantes y las escenas de crímenes en Ciudad Juárez. En una escena, uno de los reclusos del CEREso de la localidad caracteriza en estos términos al sicario, tras narrar cómo torturaba y mataba a quien le ordenaran sus patrones: "tienes que hacerte frío, no tienes que tener compasión con otra gente". Ser frío es una habilidad central para el trabajo criminal, implica la desafección entre el victimario y su víctima.

Todo parece, entonces, correr a favor de la ideología implícita en el mercado ilegal: poder a través del dinero, goce del privilegio de la impunidad y una presencia pública como fuerza de terror. Para Rita Segato (2003:271-276), los feminicidios de Ciudad Juárez, más que muertes instrumentales, son muertes expresivas: se despliegan ante la mirada de los vivos como una demostración de poder; producen y reproducen impunidad, en el sentido de que esta es un privilegio que los soberanos ostentan como una forma de apuntalar su poder. La impunidad no puede existir sin un pacto de complicidad entre criminales y agentes oficiales con el fin de proteger una economía de la depredación.

En su análisis de los afectos en el Antiedipo de Deluze y Guattari, Jason Read (2014) señala un proceso de reducción en el sistema capitalista que nos permite explicar la desechabilidad que sustenta a este sistema depredatorio: "a general critique of the reduction of the entire level of affect to consumption and representation, the reduction of intensity to extension, and production to representation". Todo afecto posible en las prácticas de violencia sexogenérica se reduce al consumo, a literalmente la extinción de un cuerpo en favor de la satisfacción de los consumidores-depredadores. La violación y muerte de una víctima para expresar el afecto del odio es en sí una satisfacción donde se ejercen emociones intensas, que han superado intensidades previas, en una economía de la crueldad que requiere de esta escalada para desplegar su poder. Esto es, el poder puede medirse según la intensificación de la crueldad. El afecto que se genera dentro de la lógica de la producción y el consumo es el cinismo: el cinismo es indiferente a los axiomas que reproducen la vida "the recognition that the flows of the market mean nothing, have no justification, than their brute effectivity" (Read, 20I4).

En su vaciamiento moral, el acto justificado solamente por la lógica del mercado no es más que una manifestación de una doble pasividad: la del Estado ante el mercado criminal y la del propio individuo que consume violentamente (o consume las emociones extremas y los privilegios simbólicos de la violencia) sujetándose a una norma de deseo a partir de la priorización del goce destructivo sobre cualquier 
otro tipo de afecto. Esta obediencia a las normas de la violencia, esta docilidad a los mandatos de un sistema destructivo nos remite a la noción de banalidad del mal de Hanna Arendt (1964:105-106). Según Arendt, el ejecutor de la violencia no se ve a sí mismo como quien haya ejercido su propia voluntad de exterminio sino que se presenta como alguien que tuvo que cumplir con una tarea que se le ordenó. Tanto el personaje Verguillas como los sicarios descritos en los corridos del Movimiento Alterado se presentan como peones de un sistema económico donde es su capacidad destructiva lo que en ellos se valora: se trata de banalizar actos de lesa humanidad mediante el discurso de la eficiencia y el circuito de producción/consumo.

Entender el exterminio de las mujeres desde la óptica del imaginario del consumo establece una relación de continuidad entre los signos de la ostentación de la llamada narcocultura y el exceso homicida, todos ellos comprendidos bajo la noción de bienes de consumo violento.

\section{Conclusiones}

El sistema de victimización por violencia de género esbozado en este trabajo parece dejar a la víctima en una pasividad inexorable. La ciudadanía parece contar con muy precarios recursos para evitar una violencia que le es en gran medida incomprensible. Al inicio del documental Narcocultura (2013) tres niños relatan un homicidio del que fueron testigos. Con perplejidad juzgan la falta de justificación de los hechos de sangre: "A lo menso... todavía dijeras: 'van tras de uno' No, tiran a lo menso". No hay razón lógica para muchos de los asesinatos, de no ser la de aterrorizar indistintamente a la población.

Se diría que este terror ha enmudecido e inmovilizado a la sociedad civil, pero los impulsos de una razón comunitaria desmienten tal fatalismo. En esos mismos barrios abandonados por el Estado y consumidos por el mercado letal hemos sido testigos de expresiones colectivas que tienden a la recuperación del espacio urbano y a la creación de lazos sociales que se manifiestan críticamente contra la victimización. Así, se han formado en Ciudad Juárez, Tijuana, Hermosillo, Oaxaca, Guadalajara y el Distrito Federal diversos colectivos de arte urbano que cubren las paredes con su crítica derechohumanista: tales son los casos de Hecho en México, en Tijuana, y Reziste en Ciudad Juárez, dos bastiones de la acción comunitaria en contexto de violencia. Perder el miedo a partir de la fe en la comunidad es un discurso que emerge de estos paisajes periféricos. La emergencia de recuperar la ciudad ha motivado un número amplio de trabajos de cine documental, literatura, proyectos de animación, 
blogs y una creciente participación en redes sociales. Gracias a esta multiplicidad de expresiones es que podemos asomarnos a la subjetividad de los victimarios de la violencia sexogenérica, la que aquí a grandes rasgos caracterizamos como: afirmada en un odio piadoso hacia lo femenino y no heterosexual; reforzada por un clima de impunidad en un Estado dominado por los poderes criminales; y articulada como una economía consistente en consumir cuerpos desechables. Tal es el monstruo que la imaginación colectiva tendrá que exorcizar.

\section{Bibliografía}

Aguilar, Julián (2012),"Mexicans Seeking Refuge Come Together to Speak Out", The Texas Tribune (13 de abril), <www.texastribune.org/2012/04/13/ mexicans-seeking-refuge-come-together-speak-out/ $>$, [ Io de junio de 2014].

Amorós, Celia (1985), Hacia una critica de la razón patriarcal, Anthropos, Barcelona.

Arendt, Hanna (1964), Eichmann in Jerusalem: A Report on the Banality of Evil, The Viking Press, Nueva York.

Benítez Rhory et al. (1999), El silencio que la voz de todas quiebra. Mujeres y víctimas de Ciudad Juárez. Chibuabua, Ediciones del Azar-Universidad Autónoma de Ciudad Juárez, México, 1999.

Biron, Rebecca (2000), Murder and Masculinity: Violent Fictions of 2oth Century Latin America, Vanderbilt University Press, Nashville.

Butler, Judith (1997), Excitable Speech. A politics old the Performative, Routledge, Nueva York.

Careaga, Gloria (en prensa) "La homofobia en la violencia de las relaciones heterosexuales”, en Héctor Domínguez Ruvalcaba (comp.), La cuestión del odio: acercamientos interdisciplinarios a la violencia homofóbica en México.

Carrera, Carlos (dir.) (2009), Traspatio, argumento de Sabina Berman, Inbursa/ Fondo para la Producción Cinematográfica de Calidad/Argos, México

Chacón, Armando, Luis Saucedo y Salvador Chacón, (2009) El Verguillas. Parte I, FAS Comedy, Ciudad Juárez, disponible en <www.youtube.com/watch?v=zhm6qstdn6M>

Eagleton, Terry (2010), On Evil, Yale University Press, New Heaven.

Lagarde, Marcela (20II),"Claves feministas en torno al feminicidio. Construcción teórica, política y jurídica”, en Linda Fregoso (comp.), Feminicidio en 
América Latina, Rosa-Universidad Nacional Autónoma de México, México.

Monsiváis, Carlos (2006), 'El sádico' y los crímenes de odio", El Universal (29 de enero), <www.eluniversal.com.mx/editoriales/33172.html $>$ [28 de junio de 20I4].

Monsiváis, Carlos (2010), Los mil y un velorios. Crónica de la nota roja en México, Random House Mondadori, México.

Morales, Héctor Alonso (2014), "Piden gritar 'tuzo' y no pu... a arquero rival", El Universal (I8 de mayo), <www.eluniversal.com.mx/deportes/20I4/ tuzo-homofobia-campana-arquero-rival-puto-IoIII38.html $>$ [Io de junio de 20I4].

Odier, Charles (196I), La angustia y el pensamiento mágico. Ensayo de análisis psicogenético aplicado a la fobia y a la neurosis de abandono. Fondo de Cultura Económica, México.

Portillo, Lourdes (dir.) (200I), Señorita Extraviada [Missing Young Woman], Women Make Movies, Nueva York.

Radford, Jill, y Diana Russell (comps.) (1992), Femicide: The Politics of Woman Killing, Twayne, Nueva York.

Read, Jason (2014), "Unemployed Negativity", Deleuze and the Passions. Conferencia anual, Erasmus University Rotterdam (I6 de mayo), http:// www.unemployednegativity.com/2014/05/the-affective-economy-producing-and.html?spref $=\mathrm{fb}$ [17 de mayo de 20I4].

Resédiz, Francisco (2013),"La AFI captura a El Sádico, asesino serial de homosexuales", Crónica.com.mx, in de febrero, <www.cronica.com.mx/ notas/2006/223065.html $>$ [ 23 de junio de 2014].

Schwarz, Shaul (dir.) (2013), Narcocultura, Ocean Size Pictures, Parts and Labor, EUA-México.

Segato, Rita Laura (2003), Las estructuras elementales de la violencia, Universidad Nacional de Quilmes, Bernal.

Vila, Pablo (2000), Crossing Borders, Reinforcing Borders: Social Categories, Metaphors, and Narrative Identities on the 2000, The University of Texas Press, Austin.

Wright, Melissa (2006), Disposable Women and Other Myths of Global Capitalism (Perspectives on Gender), Routledge, Nueva York-Londres.

Zemelman, Hugo (2000), Conocimiento y sujetos sociales. Contribución al estudio del presente (1987)El Colegio de México, México. 
El economista (2013) “México ocupa segundo lugar en crímenes de odioः IKOS» (I7 de mayo), <eleconomista.com.mx/sociedad/2013/05/17/mexico-ocupa-segundo-lugar-mundial-crimenes-odio-ikos $>$ [Io de junio de 20I4] El Universal (2014), "Instruye GDF instrumentar acciones contra la homofobia" (I9 de mayo de 20I4), <www.eluniversal.com.mx/ciudad-metropoli/20I4/gdf-implementar-acciones-contra-homofobia-Ior1392.html> [ro de junio de 20I4]

Sinembargo (2014), "Cadena de radio grupera usa clichés y denigra a las mujeres para promoverse; gobierno exige disculpa pública” (I2 de mayo), <www. sinembargo.mx/I2-05-2014/990509> [I5 de mayo de 2014]. 